\title{
МЕЖДУНАРОДНЫЙ УГОЛОВНЫЙ СУД: ПОПЫТКА ОЦЕНКИ
}

\begin{abstract}
Аннотация. Статья посвящена деятельности Международного уголовного суда. Рассматриваются отдельные аспекты его деятельности, судопроизводства и его эффективности. Автор считает, что в настоящее время Международный уголовный суд является крупным и влиятельным международным судебным учреждением, обладающим иелым рядом уникальных черт. Одна из них - наличие Прокурора, которого нет больше ни в одном международном суде. Именно Прокурору отведена роль приведения в действие юридических рамок Римского статута, а также Правил процедуры и сбора доказательств в иелях наиболее эффективного развития системы расследования и судебного рассмотрения представляемых МУС дел, а такље других методов работы; непосредственной задачей Прокурора является достижение справедливости и эффективности всей работы МУС. Без Прокурора и его Офиса МУС, вероятно, вообще не смог бы действовать.Автор обращяет внимание и на другой недостаток сказывающийся на эффективной деятельности МУС - трудность сбора доказательств и проведения расследований относительно массовых преступлений.
\end{abstract}

Ключевые слова: международное право, международный суд, ООН, эффективность, судопроизводство, история, прокурор, судебное решение, преиедент, процесс

Abstract: The article is devoted to the activities of the International Criminal Courts, some aspects of its activities, judicial proceedings and efficiency. The author considers that currently the ICC is a large and influential judicial body, and it has a range of unique features. One of such features is presence of a Prosecutor, and such a position is not present in any other international court. The Prosecutor implements the legal framework of the Roman Statute as well as The Rules of Procedure and Evidence in order to guarantee the most efficient development of the investigation and judicial proceedings of the ICC cases, as well as to other working methods. The immediate task of the Prosecutor is to guarantee justice and efficiency throughout the spheres of work of the ICC. The ICC probably would not be capable of working without the Prosecutor and his Office. The author pays attention to a defect influencing the efficiency of the ICC activities concerning hardships in collection of evidence and investigation on mass crimes.

Keywords: international law, international court, the UN, efficiency, judicial proceedings, history, Prosecutor, judicial decision, precedent, process.

Международном уголовном суде написано уже чрезвычайно много, и в российской ${ }^{1}$, и особенно в западной литературе ${ }^{2}$.

\footnotetext{
${ }^{1}$ Блищенко И.П. , Фисенко И.В. Международный уголовный суд. М., 1998; Лукашук И.И. Международный уголовный суд // Российский юридический журнал. 1999. № 2; Шабас У. Международный уголовный суд: исторический шаг в деле борьбы с безнаказанностью// Московский журнал международного права. - 1999. - № 4; Подиибякин А.С. Международный уголовный суд и проблемы национального законодательства // Международное уголовное право и международная юстиция. 2008. № 1 .

${ }^{2}$ См., например: Sadat L. N., The International Criminal Court and the Transformation of International Law: Justice for the New
}

Поэтому здесь остановимся только на общей оценке этого судебного учреждения в плане тех функций, которые должны исполняться системой международного правосудия.

Международный уголовный суд (МУС) это первый постоянный международный трибунал, основанный на договоре, созданный с целью уголовного преследования индивидов за наиболее серьезные преступления по международному праву, от имени международного сообщества в целом в тех случаях, когда

Millennium . NY, 2002; Cassese A., Gaeta P. , Jones J. (eds) The Rome Statute of the ICC Oxford, 2002. 
национальные юрисдикции не намерены или не в состоянии осуществить действенное расследование или наказание. МУС в целом расценивается как значительный шаг вперед в деле придания эффективности международному уголовному праву

МУС был создан в соответствии с Римским Статутом, принятым 120 государствами 17 июля 1998 г. ${ }^{4}$, который вступил в силу 1 июля 2002 г., после получения Генеральным секретарем ООН 66 ратификационных грамот. В настоящее время юрисдикцию МУС признали 105 государств; однако такие крупные державы постоянные члены Совета Безопасности, как Китай и США, не признали его. Россия подписала Статут, но не ратифицировала.

Согласно Статуту МУС, он призывает к ответственности индивидов за совершение наиболее тяжких и широкомасштабных нарушений общих ценностей человечества. Его создатели ставили цель предотвратить избежания наказания потенциальных преступников во всем мире, особенно тех из них, кто занимает высокие должностные позиции, так что их охраняет иммунитет государства.

Вторая цель МУС - это укрепление солидарности всего международного сообщества в деле защиты интересов жертв международных преступлений. Он должен быть свободен от политических или иных не относящихся к делу доводов.

Институт, созданный согласно Римскому статуту - это типичный независимый международный суд, состоящий из независимых судей, избираемых в личном качестве. В состав МУС входит три палаты: досудебная (решает в основном вопросы подсудности и приемлемости иска), судебная (ведет судебное рассмотрение дела и решает вопросы виновности подсудимого) и апелляционная (рассматривает апелляции на решение досудебной и судебной палат).

\footnotetext{
${ }^{3}$ Lee R.S. (ed). The International Criminal Court: The Making of the Rome Statute (Kluwer The Hague 1999).

${ }^{4}$ Rome Statute for an International Criminal Court. UN Diplomatic Conference of Plenipotentiaries on the Establishment of an International Criminal Court (17 July 1998) UN Doc A/ CONF.183/9
}

Офис прокурора - это независимый орган МУС, уполномоченный принимать и рассматривать сообщения и информацию о преступлениях, а также вести расследование. Согласно сложившейся практике, прокурор уделяет особое внимание деяниям тех лиц, кто несет главную ответственность за акты государства. Полномочия прокурора довольно обширны и могут приводить к значительным последствиям. Так, по ст. 13 и 15 Статута, прокурор вправе инициировать расследование на основании исключительно его собственной оценки какой-либо ситуации или информации. Однако ему требуется предварительное одобрение досудебной палаты.

Секретариат отвечает за всю несудебную деятельность МУС.

Ассамблея государств-участников включает по одному представителю от каждого государства и осуществляет законодательные и контрольные функции: принимает самые важные документы, обеспечивает контроль за организацией МУС, принимает бюджет. Она избирает судей, прокурора и может отрешить их от должности.

МУС не обладает общей компетенцией. Один из его основных принципов - это так называемый принцип комплементарности, то есть дополнения его юрисдикцией юрисдикции национального уголовного правосудия: МУС занимается расследованием и наказанием тех деяний, которыми национальные суды не могут или не склонны заниматься. Статут содержит окончательный список подсудных ему преступлений, которые охарактеризованы как «самые серьезные преступления, вызывающие озабоченность международного сообщества в целом». Это геноцид; преступления против человечности (11 категорий деяний, представляющих собой широкомасштабные акты, направленные против гражданского населения: пытки, обращение в рабство, принудительный труд, сексуальное насилие, депортация населения, апартеид, а также иные бесчеловечные акты подобного характера); военные преступления; преступление агрессии.

Необходимо отметить, что квалификация состав наказуемых преступлений нередко 
содержит отсылку к другим международным договорам, то есть в этом плане Римский статут является частью целостной ткани общего международного права.

Важное ограничение юрисдикции МУС - это ограничение во времени: он компетентен только в отношении тех преступлений, которые совершены после вступления в силу Римского статута для первоначальных членов. Для государств, которые присоединятся к Статуту позже, соответствующей датой будет первый день месяца, следующего за 60-м днем после депонирования документа о ратификации. Однако любое государство, не участвующее в Статуте, может сделать формальное заявление о признании юрисдикции МУС в отношении определенных преступлений. Такое заявление было сделано государством Кот д’Ивуар в 2005 г.

Совет Безопасности ООН наделен правом передавать какую-либо ситуацию на рассмотрение МУС, если есть основания полагать, что совершены деяния, криминализованные по Римскому статуту, а ситуация подпадает под действие Главы VII Устава ООН; при этом нет необходимости соблюдать предварительные условия наличия юрисдикции МУС. В таких случаях могут быть затронуты и государства - не участники Статута, а правовая сила данного обязательства базируется на полномочиях Совета Безопасности. МУС при этом остается связан положениями Статута о его юрисдикции ratione materiae.

Именно это положение лежит в основе Резолюции $1593^{5}$ от 31 марта 2005 г., которой Совет Безопасности передает ситуацию в Дарфуре после 1 июля 2002 г. Прокурору МУС. В данной Резолюции нет обязательства всех членов ООН сотрудничать с МУС в ее выполнении; это значительное отличие от Резолюций Совета $827^{6}$ и 9557, которыми были предусмотрены мандаты Международного трибунала по бывшей Югославии и Международного трибунала по Руанде.

\footnotetext{
${ }^{5}$ UNSC Res 1593 (2005) (31 March 2005) SCOR [1 August 2004-31 July 2005] 131.

${ }^{6}$ UNSC Resolution 827 (1993) of 25 May 1993.

${ }^{7}$ UNSC Resolution 955 (1994) of 8 November 1994.
}

Пространственно юрисдикция МУС распространяется на деяния, совершенные на территории государства-члены, включая морской и воздушный транспорт, если подозреваемый - гражданин государства-члена. Это означает, что принцип универсальной юрисдикции не составляет часть права Римского статута, хотя в ходе Римской конференции многие государства считали, что следует распространить юрисдикцию МУС на территорию укрывающего государства, если оно участвует в Статуте.

Статутом установлена иерархия применяемого права. В первую очередь, это сам Статут, а также документы, принятые МУС: Кодекс судебной этики ${ }^{8}$, Кодекс профессионального поведения адвокатов 9 , Элементы преступлений ${ }^{10}$, Правила процедуры и сбора доказательств ${ }^{11}$, Регламент Суда ${ }^{12}$. Данными документами регулируется порядок действий самого Суда.

Римский статут содержит также несколько общих принципов международного уголовного права, применяемых в ходе расследования в МУС: nullum crimen, nulla poena sine lege, освобождение от ответственности лиц старше определенного возраста; уровень психического здоровья подсудимого; основания освобождения от уголовной ответственности. Есть в нем и специальные принципы: равенство; приказы начальника; ответственность командиров.

МУС применяет также договоры и нормы и принципы международного права, в том числе общепризнанные принципы права вооруженных конфликтов. Если всех указанных источников недостаточно, МУС рассматривает применимость общих принципов

\footnotetext{
${ }^{8}$ Code of Judicial Ethics (9 March 2005) Doc ICC-BD/02-01-05.

${ }^{9}$ Code of Professional Conduct for Counsel (2 December 2005) Doc ICC-ASP/4/3/Res. 1 .

${ }^{10}$ Elements of Crimes (9 September 2002) Doc ICC-ASP/1/3 (Pt. II-B).

${ }^{11}$ Rules of Procedure and Evidence (9 September 2002) Doc ICC-ASP/1/3 (Pt. II-A).

${ }^{12}$ Regulations of the Court (26 May 2004) Doc ICC-BD/01-01-04, (as revised on 9 March 2005) Doc ICC-BD/01-01-04/Rev.01-05.
} 
права, как они закреплены в национальных правовых системах.

МУС не связан своими более ранними решениями, но может опираться на них.

Процедура расследования может быть возбуждена в МУС тремя способами: односторонним обращением государства к Прокурору ${ }^{13}$; по собственной инициативе Прокурора; по инициативе Совета Безопасности ООН ${ }^{14}$.

Предварительный анализ проводится Прокурором, в частности, решение вопроса о том, имеется ли достаточное основание для дальнейших действий.

Когда подозреваемое лицо передано МУС, приступает к деятельности Доследственная палата, которая должна убедиться в том, что это лицо проинформировано о выдвигаемых против него обвинениях и в их обоснованности.

Судебное следствие проводится публично и в нем должны быть обеспечены права и защита потерпевших и свидетелей. Присутствие обвиняемого обязательно. Ведущий принцип разбирательства - презумпция невиновности.

В МУС возможны несколько способов обращения обвинения, обвиняемого или прокурора к апелляции, на основании процессуальной ошибки, фактической ошибки или юридической ошибки.

Стороны в процессе могут также обратиться за апелляцией в отношении не только окончательного приговора, но и вопросов приемлемости иска или юрисдикции, а также промежуточных решений. Возможен и полный пересмотр приговора.

Для процесса в МУС характерны некоторые особенности. Большое значение в нем придается соблюдению прав обвиняемого

\footnotetext{
${ }^{13}$ Именно такими были три первые обращения: Уганда, Демократическая Республика Конго, Центрально-Африканская республика.

${ }^{14}$ Своеобразным примером здесь служит Резолюции Совета Безопасности 1422 и 1487, принятые по инициативе США, где со ссылкой на ст.16 Римского статута, предлагалось изъять военнослужащих миротворческих сил $\mathrm{OOH}$ - граждан государств, не участвующих в Статуте, из юрисдикции МУС. См.: UNSC Resolution 1422 (2002) of 12 July 2002 and UNSC Resolution 1487 (2003) of 12 June 2003.
}

не только во время самого процесса, но и на доследственной стадии. Запрещено насилие, принуждение, угрозы, пытки или иные формы жестокого и бесчеловечного обращения; запрещены произвольный арест, задержание или лишение свободы; Никто не может быть принужден давать показания против себя и каждый имеет право на помощь квалифицированного переводчика.

Весьма важный аспект справедливого разбирательства - предоставление Прокурором доказательств защите. Это касается не только тех доказательств, которые Прокурор намерен использовать в процессе, но также и тех, которые могут быть реабилитирующими, а потому особенно важными для защиты.

МУС по собственной инициативе, или по просьбе, принимает необходимые меры для защиты безопасности, физического и психологического благополучия, достоинства и неприкосновенности частной жизни потерпевших и свидетелей. Формами защиты могут быть рассмотрение в камере, аудиовизуальное или электронное представление доказательств. В Секретариате МУС образован специальный отдел потерпевших и свидетелей, который оказывает им консультативную или организационную помощь. Однако эти меры не должны снижать значение мер защиты, предоставляемых обвиняемому.

Новация Римского статута - то внимание, которое уделяется интересам потерпевших, в частности, путем предоставления им активной роли в разбирательстве. Правда, пока не совсем ясно, как должен достигаться баланс в правах потерпевших и обвиняемых. В соответствии с Решением Досудебной палаты 2006 г. ${ }^{15}$ потерпевшие имеют право участвовать в стадии расследования, то есть еще до выдачи ордера на арест обвиняемого. Уже на этой стадии они должны показать, что имеется достаточно оснований для утверждения о том, что им был нанесен вред. Иные лица, в особенности неправительственные организации вправе делать представления от имени потерпевших с их согласия.

\footnotetext{
${ }^{15}$ Pre-Trial Chamber I Decision of 17 January 2006 regarding the situation in the Democratic Republic of Congo.
} 
МУС может распорядиться о выплате потерпевшему возмещения со стороны обвиняемого, а потерпевший - обратиться за таким возмещением. Ассамблея государств-участников МУС образовала трастовый фонд, из которого могут выплачиваться возмещения.

МУС не имеет собственных способов обеспечивать исполнение своих приговоров и полагается в этом на государства. С этой целью МУС подписывает соглашения с теми государствами, которые согласны принять осужденных для отбывания наказания ${ }^{16}$.

Поскольку МУС вообще сам не имеет исполнительных полномочий или полицейских сил, сотрудничество с государствами и содействие их судебных органов жизненно важно для него, особенно в вопросах осуществления ордеров на арест и передачи подозреваемых. $\mathrm{B}$ целях гарантий такого сотрудничества со стороны государств к Римскому статуту не допускаются оговорки.

Сотрудничество с ООН обеспечивается на основе Соглашения о взаимодействии ${ }^{17}$. Кроме закрепления в нем взаимного признания общепризнанных принципов международного права, это соглашение создает правовую основу для взаимодействия в борьбе против тяжелых нарушений международного права. В нем также содержится обязательство предоставления Генеральному секретарю ООН права постоянного присутствия в палатах и публичных мероприятиях МУС; Суду, в свою очередь, предоставлен статус наблюдателя при ООН. Предусмотрен также обмен информацией и документами, представляющими взаимный интерес.

Римским статутом не предусмотрено создание какого-либо организационного механизма, так что отношения между МУС и государствами-участниками характеризуются как «горизонтальные». Целый ряд государств-участников Статута включили

\footnotetext{
16 Первым государством, подписавшим соответствующее соглашение с МУС в 2005 г., была Австрия, вторым Великобритания, подписавшая соглашение в 2007 г.

${ }^{17}$ Negotiated Relationship Agreement between the International Criminal Court and the United Nations (4 October 2004) Doc ICC-ASP/3/Res.1.
}

соответствующие положения в свое национальное законодательство. Главное обязательство государств-участников - в полной мере сотрудничать с МУС, что выражается в задержании подозреваемых, обнаруженных на их территории, и передаче их МУС; предоставлении информации и доказательств, осмотр места происшествия - словом, совершение действий, способствующих исполнению функций МУС.

Особый интерес для нас представляют отношения между МУС и третьими странами. Эти страны не связаны общим обязательством сотрудничества с МУС. Однако, если Совет Безопасности передает какую-либо ситуацию МУС, он может также, действуя по Главе VII Устава, обязать третье государство сотрудничать с МУС. Таким образом обычно толкуются события в связи с передачей Советом Безопасности ситуации в Дарфуре; поскольку Судан, частью которого является Дарфур, не участвует в Статуте, Совет решил, что Судан должен в полной мере сотрудничать с МУС и предоставить все необходимое содействие.

Римский статут также предусматривает, что третьи страны могут быть приглашены к сотрудничеству с МУС путем предоставления информации и иной правовой помощи на основе общего соглашения или соглашения ad hoc.

Одна необычная для международных судов черта касается сбора и получения свидетельских показаний. Дело в том, что МУС признает частных лиц и неправительственные организации как важный источник информации, особенно поступающей с непосредственного места совершения преступления, учитывая их возможные тесные связи с потерпевшими и с местными организациями правозащитников. Такая информация в международном судебном процессе именуется «письма друзей суда» (amicus curiae letters) и, как правило, не допускается для использования в качестве доказательств. Первый случай допущения «писем друзей суда» был отмечен в работе Органа по разрешению споров Всемирной торговой организации. 
В МУС информация, поступающая от неправительственных организаций и из иных частных источников, принимается Офисом Прокурора на самой ранней стадии подготовки дела к рассмотрению, когда решается вопрос о самом начале разбирательства. Прокурор должен проанализировать поступившую информацию и сообщить источнику о своей оценке этой информации и о выводах относительно начала разбирательства. Прокурору дается также право самому запрашивать информацию от неправительственных организаций и иных надежных источников.

В некоторых случаях допускается даже использование Прокурором волонтеров, предоставляемых неправительственными организациями, для содействия работе тех или иных органов МУС.

$$
* * *
$$

Таким образом, в настоящее время Международный уголовный суд является крупным и влиятельным международным судебным учреждением, обладающим целым рядом уникальных черт.

Одна из них - наличие Прокурора, которого нет больше ни в одном международном суде. Прокурор и его офис, это, по мнению многих исследователей, движущая сила или «мотор» МУС $^{18}$. Именно Прокурору отведена роль приведения в действие юридических рамок Римского статута, а также Правил процедуры и сбора доказательств в целях наиболее эффективного развития системы расследования и судебного рассмотрения представляемых МУС дел, а также других методов работы; непосредственной задачей Прокурора является достижение справедливости и эффективности всей работы МУС. Без Прокурора и его Офиса МУС, вероятно, вообще не смог бы действовать.

Прокурор также играет немалую роль в налаживании сотрудничества МУС с государствами и международными организациями.

${ }^{18}$ Danner A.M. Enhancing the Legitimacy and Accountability of Prosecutorial Discretion at the International Criminal Court// AJIL, v.97, 2003, p. 510.
Благодаря усилиям Прокурора выстраивается целая сеть надежных связей международного сотрудничества с государствами-участниками, третьими странами и иными акторами международных отношений ${ }^{19}$.

Необходимо отметить и некоторые ограничения, препятствующие эффективной деятельности МУС. Самая большая трудность - сбор доказательств и проведение расследований относительно массовых преступлений, которые совершаются в таких районах, которые, как Уганда, Конго, Дарфур, нестабильны и отнюдь не безопасны.

Расположение МУС вдали от мест совершения преступлений также играет свою отрицательную роль, хотя в Статуте есть положения, позволяющие МУС проводить свои заседания не в штаб-квартире, а в других местах.

Пока еще, пожалуй, трудно делать такие далеко идущие выводы, как создание, благодаря МУС, «новой системы международной уголовной юстиции, состоящей из двух дополняющих друг друга уровней» ${ }^{20}$.

Гораздо более взвешенной представляется оценка, сделанная Б.Р.Тузмухамедовым: «МУС - по-прежнему юный и все еще незрелый организм. Он до сих пор не разрешил ни одного дела. По выданным им ордерам арестованы едва ли четверо подозреваемых, a попытка заполучить президента Судана Омара аль-Башира вызвала скандал и неповиновение. Оптимизм, сопутствовавший его созданию, умерился" 21.

МУС - довольно смелая попытка создать новую систему правосудия. Хотя МУС сильно отличается от «классических» международных судов, с течением времени он может стать полезным элементом поддержания международного правопорядка.

\footnotetext{
19 См.: Землянская В.В. Актуальные вопросы международного сотрудничества Международного уголовного суда// Международное уголовное правосудие. С.418.

${ }^{20}$ Benzing $M$. The Complementarity Regime of the International Criminal Court: International Criminal Justice between State Sovereignty and the Fight against Impunity//Max Planck United Nations Yearbook, v.7, 2003, p. 631.

${ }^{21}$ Тузмухамедов Б.Р. Юридические споры в Кампале//Независимая газета, 2010, 6 июля.
} 


\section{Библиография:}

1. Benzing M. The Complementarity Regime of the International Criminal Court: International Criminal Justice between State Sovereignty and the Fight against Impunity//Max Planck United Nations Yearbook, v.7, 2003, p. 631.

2. Danner A.M. Enhancing the Legitimacy and Accountability of Prosecutorial Discretion at the International Criminal Court// AJIL, v.97, 2003, p. 510.

3. Sadat L. N., The International Criminal Court and the Transformation of International Law: Justice for the New Millennium . NY, 2002;

4. Cassese A., Gaeta P., Jones J. (eds) The Rome Statute of the ICC, Oxford, 2002.

5. Блищенко И.П. , Фисенко И.В. Международный уголовный суд. М., 1998;

6. Землянская В.В. Актуальные вопросы международного сотрудничества Международного уголовного суда//Международное уголовное правосудие. С.418.

7. Лукашук И.И. Международный уголовный суд // Российский юридический журнал. 1999. № 2 ;

8. Шабас У. Международный уголовный суд: исторический шаг в деле борьбы с безнаказанностью// Московский журнал международного права.-1999.-№ 4;

9. Подшибякин А.С. Международный уголовный суд и проблемы национального законодательства // Международное уголовное право и международная юстиция. 2008. № 1.

10. Р.А. Каламкарян, Ю.И. Мигачев. Всеобщая Декларация прав человека: роль и значение в условиях миропорядка на основе господства права Rule of Law. // Право и политика. 2008. - № 12. - C. 104-107.

11. Р.А. Каламкарян. Всеобщая декларация прав человека-60 лет. Позитив международно-правового опыта. // Право и политика. - 2008. - № 11.

12. Г.Г. Шинкарецкая. Изъятие из компетенции судебных учреждений дел, относящихся к внутренней компетенции государства // Право и политика. - 2010. - № 3.

13. Г.Г. Шинкарецкая. Запрет злоупотребления международной судебной процедурой как фактор обеспечения судебного процесса // Право и политика. - 2010. - № 2.

14. Каламкарян Р.А. Роль Международного Суда ООН в деле поддержания международного правопорядка // NB: Международное право. - 2013.-№ 1.-C.184-214. DOI: 10.7256/23069899.2013.1.690. URL: http://e-notabene.ru/wl/article_690.html

15. Каламкарян Р.А. Включенность Российской Федерации в деятельность Международного Суда ООН в деле обеспечения международной законности и правопорядка // NB: Международное право. - 2013.-№ 2.-C.85-118. DOI: 10.7256/2306-9899.2013.2.691. URL: http://e-notabene.ru/wl/article_691.html

16. Соловьева Т.В. Об отсутствии единого нормативно закрепленного порядка приведения в исполнение постановлений Европейского Суда по правам человека. // NB: Международное право. - 2013.-№ 4.-C.184-200. DOI: 10.7256/2306-9899.2013.4.2507. URL: http://e-notabene. $\mathrm{ru} / \mathrm{wl} /$ article_2507.html

17. А. С. Смбатян. Обычные нормы международного права и общие принципы как источник судебного правотворчества // Право и политика. - 2012. - № 4. - С. 104-107.

18. А. С. Смбатян. Правотворчество международных уголовных трибуналов: опыт МУТБЮ // Право и политика. - 2012. - № 3. - С. 104-107.

19. У.А. Латыпов. Международное сотрудничество в сфере уголовной юстиции: история становления и современное состояние // Политика и Общество. - 2009. - № 11.

20. А.С. Смбатян. Органы международного правосудия: классификация в рамках общей системы // Право и политика. - 2013. - № 4. - C. 104-107. DOI: 10.7256/1811-9018.2013.04.12.

21. А. С. Смбатян. Нужно ли «спасать» систему международного судопроизводства от фрагментации? // Право и политика. - 2011. - № 9. - С. 104-107 


\section{References (transliteration):}

1. Benzing M. The Complementarity Regime of the International Criminal Court: International Criminal Justice between State Sovereignty and the Fight against Impunity//Max Planck United Nations Yearbook, v.7, 2003, p. 631.

2. Danner A.M. Enhancing the Legitimacy and Accountability of Prosecutorial Discretion at the International Criminal Court// AJIL, v.97, 2003, p. 510.

3. Sadat L. N. , The International Criminal Court and the Transformation of International Law: Justice for the New Millennium . NY, 2002;

4. Cassese A. , Gaeta P. , Jones J. (eds) The Rome Statute of the ICC, Oxford, 2002.

5. Blishchenko I.P. , Fisenko I.V. Mezhdunarodnyi ugolovnyi sud. M., 1998;

6. Zemlyanskaya V.V. Aktual'nye voprosy mezhdunarodnogo sotrudnichestva Mezhdunarodnogo ugolovnogo suda//Mezhdunarodnoe ugolovnoe pravosudie. S.418.

7. Lukashuk I.I. Mezhdunarodnyi ugolovnyi sud // Rossiiskii yuridicheskii zhurnal. 1999. № 2;

8. Shabas U. Mezhdunarodnyi ugolovnyi sud: istoricheskii shag v dele bor'by s beznakazannost'yu// Moskovskii zhurnal mezhdunarodnogo prava.-1999.-№ 4;

9. Podshibyakin A.S. Mezhdunarodnyi ugolovnyi sud i problemy natsional'nogo zakonodatel'stva // Mezhdunarodnoe ugolovnoe pravo i mezhdunarodnaya yustitsiya. 2008. № 1 .

10. R.A. Kalamkaryan, Yu.I. Migachev. Vseobshchaya Deklaratsiya prav cheloveka: rol' i znachenie v usloviyakh miroporyadka na osnove gospodstva prava Rule of Law. // Pravo i politika. - 2008. - № 12. - S. 104-107.

11. R.A. Kalamkaryan. Vseobshchaya deklaratsiya prav cheloveka-60 let. Pozitiv mezhdunarodno-pravovogo opyta. // Pravo i politika. - 2008. - № 11.

12. G.G. Shinkaretskaya. Iz"yatie iz kompetentsii sudebnykh uchrezhdenii del, otnosyashchikhsya k vnutrennei kompetentsii gosudarstva // Pravo i politika. - 2010. - № 3 .

13. G.G. Shinkaretskaya. Zapret zloupotrebleniya mezhdunarodnoi sudebnoi protseduroi kak faktor obespecheniya sudebnogo protsessa // Pravo i politika. - 2010. - № 2.

14. Kalamkaryan R.A. Rol' Mezhdunarodnogo Suda OON v dele podderzhaniya mezhdunarodnogo pravoporyadka // NB: Mezhdunarodnoe pravo. - 2013.-№ 1.-S.184-214. DOI: 10.7256/2306-9899.2013.1.690. URL: http://e-notabene.ru/wl/article_690.html

15. Kalamkaryan R.A. Vklyuchennost' Rossiiskoi Federatsii v deyatel'nost' Mezhdunarodnogo Suda OON v dele obespecheniya mezhdunarodnoi zakonnosti i pravoporyadka // NB: Mezhdunarodnoe pravo. - 2013. - № 2. - S.85-118. DOI: 10.7256/2306-9899.2013.2.691. URL: http://e-notabene.ru/wl/ article 691.html

16. Solov'eva T.V. Ob otsutstvii edinogo normativno zakreplennogo poryadka privedeniya $v$ ispolnenie postanovlenii Evropeiskogo Suda po pravam cheloveka. // NB: Mezhdunarodnoe pravo. - 2013. - № 4.-S.184-200. DOI: 10.7256/2306-9899.2013.4.2507. URL: http://e-notabene.ru/wl/ article_2507.html

17. A. S. Smbatyan. Obychnye normy mezhdunarodnogo prava i obshchie printsipy kak istochnik sudebnogo pravotvorchestva // Pravo i politika. - 2012. - № 4. - S. 104-107.

18. A. S. Smbatyan. Pravotvorchestvo mezhdunarodnykh ugolovnykh tribunalov: opyt MUTBYu // Pravo i politika. - 2012. - № 3. - S. 104-107.

19. U.A. Latypov. Mezhdunarodnoe sotrudnichestvo v sfere ugolovnoi yustitsii: istoriya stanovleniya $\mathrm{i}$ sovremennoe sostoyanie // Politika i Obshchestvo. - 2009. - № 11.

20. A.S. Smbatyan. Organy mezhdunarodnogo pravosudiya: klassifikatsiya v ramkakh obshchei sistemy // Pravo i politika. - 2013. - № 4. - S. 104-107. DOI: 10.7256/1811-9018.2013.04.12.

21. A. S. Smbatyan. Nuzhno li «spasat'» sistemu mezhdunarodnogo sudoproizvodstva ot fragmentatsii? // Pravo i politika. - 2011. - № 9. - S. 104-107 